\title{
COVID-19 and its Challenges for the Healthcare System in Pakistan
}

\author{
Atiqa Khalid ${ }^{1}$ (D) Sana Ali $^{2}$ (D)
}

Received: 4 June 2020 / Revised: 15 July 2020 / Accepted: 16 July 2020 /

Published online: 13 August 2020

(C) National University of Singapore and Springer Nature Singapore Pte Ltd. 2020

\begin{abstract}
This article aims to highlight the healthcare issues raised by COVID-19 in Pakistan's scenario. Initially, Pakistan lacked "standard operating procedures," and the government had to ship testing kits from China and Japan. Moreover, due to violations of the lockdown and standard operating procedures (SOPs), the rapidly increasing number of cases created a burden on the healthcare system. More and more, this pandemic and its impact have grown. As vaccine development has not been successful yet, "herd immunity" can only be achieved if about three quarters of the population contract the virus - requiring immunocompromised citizens to be sacrificed for the sake of the country. Moreover, Pakistan has limited testing capacity, so most COVID-19 tests are missing their mark even as the virus spreads. The current scenario is also raising several concerns about the capacity of the government to tackle the prevailing healthcare crisis. In this regard, healthcare professionals suggest that the government must act responsibly to ensure better security provided to healthcare professionals. Identifying suspected cases, introducing personal protective equipment, and taking administrative measures to ensure that better security is provided to healthcare professionals are the needs of the hour to improve outcomes of COVID-19 patients. Testing, tracking, and lockdowns must be focused on areas where clusters are detected. The healthcare professionals must be given utmost protection before this pandemic could wreak havoc in terms of fatalities. Investing in the chronically underfunded healthcare system is needed, so that Pakistan can build capacity to fight the pandemic.
\end{abstract}

Keywords COVID-19 · Healthcare crisis · Pandemic management · Indifferent attitude · Lack of facilities

Atiqa Khalid

atiqakkhalid@gmail.com

1 Sahiwal Medical College (affiliated with the University of Health Sciences, Lahore), Sahiwal, Pakistan

2 Allama Iqbal Open University, Islamabad, Pakistan 


\section{Introduction}

The new strain of the coronavirus, which is causing the current pandemic, is called COVID-19. The Chinese authorities distinguished this strain of the virus on 7 January 2020 (World Health Organization 2020a). It started to spread globally from country to country (World Health Organization 2020b) and the cases were expanding day by day (Prompetchara et al. 2020). As of June 2020, there are no successful vaccines (Ahmed et al. 2020; Prompetchara et al. 2020) and no drug treatment is specifically recommended (Sanders et al. 2020). However, convalescent plasma transfusion can be a potential treatment, but it is in experimental stages (Chen et al. 2020).

Preventive measures are highly effective to prevent its rapid spread but for these to be helpful, influential policies must be taken for appropriate health education of people. This pandemic has severely affected some countries and their healthcare systems have reached the point of exhaustion. Amid the chaos and the rising human toll, healthcare services are undergoing decentralization and fragmentation in many severely affected countries (Boccia et al. 2020). Vulnerable communities are disproportionately impacted in this catastrophic situation. This pandemic is relentless. In a crisis-stricken world gripped by challenges, it has exposed the vulnerabilities of the global capitalist system, driven by the delayed response (Yang and Wang 2020). An avalanche of cases has overburdened healthcare structures in developed countries. In developing nations with long neglected and underfunded public health sectors, the pandemic is leading to mayhem (Gates 2020). Experts fear if its spread is not curtailed by taking bold steps and consistent management choices, it may result in unprecedented human catastrophe (Prompetchara et al. 2020). The 2019-2020 COVID-19 pandemic began to spread across Pakistan in February 2020. This paper provides an account of the governmental and institutional response to COVID-19 in Pakistan. It explains some of the severe economic and social constraints that have hindered an effective response, and it critically analyzes the policy of pursuing herd immunity. The paper ends with some key take-home messages about lessons to be learned from Pakistan's experience.

\section{COVID-19 in Pakistan}

The current COVID-19 pandemic has cut a swath around the globe due to decentralization and fragmentation of healthcare services in many severely affected countries (Armocida et al. 2020). The COVID-19 outbreak has affected the whole world. However, the situation is comparatively worse in the countries having weak healthcare strategies and system. This has become an intense catastrophe due to a brisk increase in the pandemic outbreak from region to region (Lai et al. 2020). The Chief of the World Health Organization, Tedros Adhanom Ghebreyesus, urged countries to invest in getting their healthcare system rather than to scramble for solutions when the next pandemic arrives as it is stated "we cannot continue to rush to fund panic but let preparedness go by the wayside. The world spends \$7.5 trillion annually on health" (World Health Organization 2020a). Especially in Pakistan, this pandemic has been a rude wake-up call regarding our weak health infrastructure as it comes under unbearable strain during this period 
(Spinelli and Pellino 2020). Thus, the 2019-2020 COVID-19 pandemic was affirmed to reach Pakistan in February 2020, with over 255,769 cases and 5386 deaths, as of 15 July 2020 (World Health Organization 2020b).

\section{Lack of Medical Facilities}

As a middle-income country, with a weak healthcare infrastructure and a population of around 197 million (Hayat et al. 2020), Pakistan is vulnerable to COVID-19 (Raza et al. 2020). The Federal Minister of Health reported the first two confirmed cases of COVID-19 on 26 February 2020 in Karachi and Islamabad (Ali et al. 2020). Within 12 days, the number of cases reached 20 with 5 cases in Gilgit-Baltistan, 14 cases in Sindh, and 1 in Baluchistan. Bordered with the epicenter of the pandemic, China and Iran, its geographical location required highly influential policies and strategies to counteract against the situation (Saqlain et al. 2020). According to the World Health Organization (2020c), countries should take all the preventive measures to limit the virus transmission by continuous surveillance, quarantine, awareness campaigns, and early detection. Besides, counteracting against other healthcare challenges is a major concern today (United Nations 2020). On the contrary, during the first few days, Pakistan lacked medical facilities and suspected samples were sent to China (Khanain 2020). Moreover, only a few specific quarantine centers were present with limited diagnostics and treatment facilities (92 News 2020) until the government received primers, testing kits, and equipment from other countries. As of 27 June 2020, many testing centers were available in Pakistan (Khanain 2020). The World Health Organization also established test centers for COVID-19 in seven hospitals countrywide (Saqlain et al. 2020). Initially, only a few quarantine centers were present in Pakistan. However, over time, more were established with foreign assistance. Still, centers ran out of rooms. Moreover, before the pandemic, sufficient facemasks were available to fulfill the needs of the general public, but with increased infection rate and exporting them, they became scarce and costly. Many drugs and equipment needed during the time of pandemic ran short in the pharmacies and stockiest started their business. But the Government of Pakistan took actions and the situation is now under control (Daily Times 2020a, b). Similarly, Karachi, Lahore, and southern Sindh provinces, which make up more than 70,000 of the country's 98,000 cases, have just 14,000 beds including both private and state-run hospitals. Dozens of patients were contacting hospitals' administrations but due to lack of medical facilities, hospitals are unable to provide enough medical assistance (Latif 2020a). Quarantine centers were established in Baluchistan but they lacked standard care and screening process (Khan 2020a).

As the cases of COVID-19 grew in Pakistan, hospitals groaned under the weight of patients. Government policies have failed due to the indifferent attitude of the public. The advice of public health officials was disregarded (Kermani 2020) and the government eased lockdown (Hashim 2020b). A bitter harvest was reaped from this decision. Caregivers were stressed, laboratory facilities were strained, and emergency rooms overflowed with infected patients. Likewise, the workforce dwindled, ICUs ran short of space, and the cost of care has increased (Hashim 2020a). 
Even basic medical equipment was dysfunctional and there was lack of doctors and paramedical staff. No specialized training was provided to health professionals regarding the pandemic (Jaffery 2020). Expensive medical equipment remained nonfunctional for years. Elite class got a preferential treatment leaving poverty-stricken people behind (Hadid and Sattar 2020). Even maintenance and repair of healthcare facilities was also ignored. Moreover, it was not unusual to witness scenes of general public smashing hospital equipment. Grief of death of their loved ones turned into pandemonium as it was solely "mistake of doctors." Angry families were beating doctors and ransacking hospitals as healthcare professionals turn away COVID-19 patients-saying their facilities were already in short supply (Kermani 2020). COVID-19 cases spike can quickly overwhelm Pakistan's healthcare system. As it seems this pandemic was here to stay. The state had a shortage of medical equipment and personnel and obsolete infrastructure (Afzal 2020).

Preliminary researches suggest that plasma of recovered patients contain antibodies that can be helpful for infected patients (Duan et al. 2020) but COVID-19 pandemic had sadly brought out the worst in the people of Pakistan. Instead of donating plasma as a noble gesture to help those suffering from this potentially fatal disease, recovered patients were making it their business. Convalescent plasma transfusion was not cure but a line of therapy and still in experimental stages. It should only be employed in controlled settings. Under no circumstances, should public be experimenting it without doctors' approval (Epstein and Burnouf 2020). Similarly, different drugs including dexamethasone were no more available in pharmacies as they were declared helpful for COVID-19 patients (Qureshi 2020). Therefore, much more efforts are needed to cope with the situation. Experts fear if its spread is not curtailed by taking bold steps and consistent management choices, it may result in unprecedented human catastrophe (Yi et al. 2020).

\section{Violation of Standard Operating Procedures}

Policies, designs, strategies, and actions to cope with infectious diseases change over time. For this purpose, standard operating procedures (SOPs) play a vital role to hinder the virus transmissions as an outbreak generally creates major challenges for the healthcare systems (Singh 2019). Besides the local healthcare system, sometimes the public also has to follow the designated SOPs to counteract against the outbreak (World Health Organization Regional Office Africa 2014). For instance, during the H1N1 outbreak in the USA, the government introduced SOPs to overcome the crisis condition. Those SOPs contained guidelines for healthcare providers, introduction of the new medical teams, and also certain precautionary measures for the public. As a result, the government effectively controlled the outbreak (Adini et al. 2010).

The spread of infection in Pakistan was lower than feared even though we have righted some wrongs and wronged some rights by not completely implementing as well as following the SOP's (Primary, and Secondary Health Care Department, Government of Punjab 2020). As unfortunately, the public in Pakistan appeared to have thrown caution to the wind, seeming to be in no mood to comply with SOPs as if it was somehow immune to the virus. They blatantly flouted government orders, underplayed the threat, and took it casually (Noreen et al. 2020). "They dithered, wavered and 
waffled. After doing this, they Flip Flopped then hemmed and hawed" wasting precious time instead of taking bold steps. After a brief hiatus, unmasked and unloved people violating lockdown seem everywhere who have recklessly abandoned all to fate and chance (Adams 2020).

Even as deaths due to this pandemic spiral, life is normalized everywhere. Due to this dangerous and cavalier attitude, a rapid jump in cases was recorded after relaxation in lockdown with total cases crossing 255,769 as of 15 July 2020. The initial public response to COVID-19 was casual and indifferent. Myths largely circulated, reinforcing an explicit violation of lockdown (ur-Rehman et al. 2020). Conservative individuals perceived this outbreak as a conspiracy to prevent their religious practices (Khattak 2020). Despite the threat, the mass events of prayers continued and public activates largely facilitated the virus transmission (ur-Rehman et al. 2020). Individual indices also came into consideration; for instance, people traveling from Spain escaped from screening both after positive test results, which further transmitted the virus to his community and family (Chaudhry 2020). Likewise, some patients also broke their quarantine camp in Sakkhar, infected several other people (ARY News 2020). Thus, this noncooperative behavior further fueled the virus transmission across the country (Javed et al. 2020).

\section{Pakistan's Current Scenario}

The current healthcare scenario (Chart 1) is unsatisfactory as Pakistan is a highly populated country, requiring a high level of sustained medical facilities. As compared to developed countries, i.e., the UK, China, and the USA, Pakistan is financially unstable and preventive measures concerning the outbreak were not followed completely (Waris et al. 2020). The current scenario of disease transmission in Pakistan is of

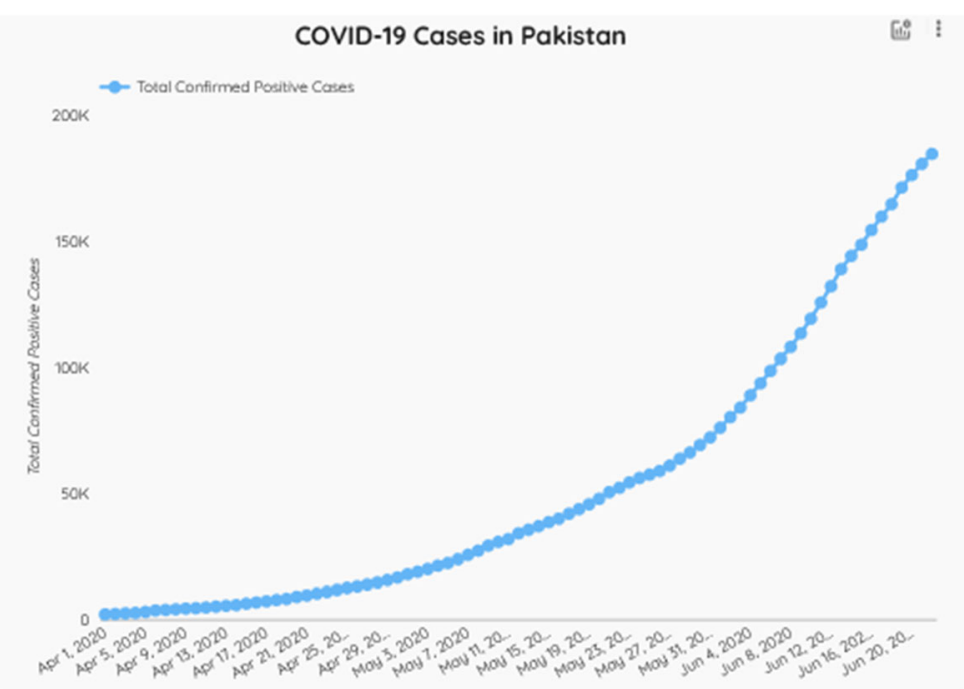

Chart 1 COVID-19 cases in Pakistan (Government of Pakistan 2020a) 
greater concern. Moreover, developing countries were comparatively more vulnerable to the healthcare crisis, and Pakistan was unable to overcome this briskly growing pandemic (Nafees and Khan 2020). As of 15 July 2020, the total 255,769 of the cases reported with 5386 deaths (Government of Pakistan 2020a). The current surge of the spread of this pandemic in Pakistan was due to the relaxation of lockdown (Adams 2020).

A number of cases were also rising due to inadequate testing facilities and fear of people to disclose the fact that they have contracted the infection. Pakistan is illprepared to encounter a crisis that can arrive in merely weeks (Javed et al. 2020).

Furthermore, China flattened the curve, giving a breather to the over-stressed health system. Curve refers to the number of people affected in a particular interval of time. The steeper the curve, the quicker a country's healthcare system will be overwhelmed, reaching its peak in a shorter duration of time. China showed systematic, comprehensive, and coordinated response through rapid self-correction and building a score of temporary hospitals and imposing countrywide lockdown. These measures lead to fruition (Liu et al. 2020). A more detailed record of confirmed cases as of 15 July 2020 is given in Table 1.

Besides, lifting lockdown for the last 3 weeks of May added 20,000 more confirmed cases as the daily aggregate of positive results escalated, on average, from 11.5 to $15.4 \%$ in the subsequent duration (Greenfield and Farooq 2020). To learn lessons through this pandemic and willing to take action (Boccia et al. 2020), many more efforts are needed instead of showing a muddled approach (Yang and Wang 2020). In this regard, the Government of Pakistan is rigorously making new policies and strategies, including awareness campaigns, quarantine facilities, testing services, and lockdown to overcome the outbreak (Waris et al. 2020). Along with the government, valiant doctors and overburdened medical staff in Pakistan are on the front line and are essential to the battle being fought against this pandemic trying to take the wild virus by the horns (Shanafelt et al. 2020). They are under tremendous stress putting themselves and their family members especially immunocompromised citizens at greater risk. By

Table 1 Detailed record of confirmed cases as of 15 July 2020 (Government of Pakistan 2020a)

\begin{tabular}{|c|c|c|c|c|}
\hline S/R no. & State/province & Confirmed & Deaths & Recovered \\
\hline 1. & Azad Kashmir & 1688 & 46 & 1049 \\
\hline 2. & Gilgit-Baltistan & 1708 & 38 & 1376 \\
\hline 3. & Punjab & 88,045 & 2043 & 64,148 \\
\hline 4. & Baluchistan & 11,239 & 127 & 7883 \\
\hline 5. & Sindh & 107,773 & 1863 & 65,420 \\
\hline 6. & KPK & 31,001 & 1114 & 21,607 \\
\hline 7. & Federal (ICT) & 14,315 & 155 & 11,327 \\
\hline
\end{tabular}

The "series" of events leading to the current crisis in Pakistan: February 2020 - first case of COVID-19 in Pakistan; March 2020 - the government took action, lockdown implemented; April 2020 -relaxation in lockdown in religious places as the government caved to demands of Muslim scholars; May 2020 - further loosening of lockdown in markets and malls imposed (during the second week of May); June 2020_lockdown reemployed. Source: Government of Pakistan (2020a) 
continuing to attend to patients, many healthcare professionals have contracted the infection (Greenberg et al. 2020). They are in constant danger as they do not have adequate personal protective equipment (PPE) and many have lost their lives (Latif 2020b).

RT-PCR done through nasopharyngeal swabs, though not a perfect test, remains the only dependable investigation as of June 2020 (Chan et al. 2020). A positive test clearly shows that a person is infected but the negative test may be false negative due to different reasons. The percentage ratio of people who have been tested positive among the entire population of those who have been tested is very low (Government of Pakistan 2020a). If people refuse to get themselves tested, the chances of community transmission will increase - because the spread of the virus to elderly, vulnerable, and immunocompromised individuals will go undetected. Therefore, it is extremely important that authorities communicate how crucial testing is and show how citizens can responsibly play their part in curbing transmission by reporting themselves if they experience COVID-19 symptoms. Such fear and reluctance will only add to the spread of the virus. The test, trace, and isolate (TTI) strategy is recommended by the World Health Organization. In Pakistan, testing capacity was half of what recommended by the World Health Organization (Hashim 2020b). However, according to Pakistan's policies, symptomatic passengers were tested and quarantined until the availability of test results. Provinces test and track the negative cases that were sent to home. Positive cases were handled as per health protocol. Positive cases belonging to other provinces were quarantined for a 14-day period by the province of arrival and could not be allowed to travel before completion of a prescribed period (Government of Pakistan 2020b).

\section{Herd Immunity}

Many government officials suggested "herd immunity" as a compelling solution to the problem. However, its implementation will be a gamble as the World Health Organization has warned developing countries regarding the potential threat (Greenfield and Farooq 2020; Husain 2020). As per noted by Fine et al. (2011), there are certain legal and ethical challenges concerning herd immunity implementation because authorities are required to pressurize, force, or entice individuals to be immunized through herd immunity. Also, immunization can have other side effects that further challenge this idea (Isaacs et al. 2009).

The first indication of herd immunity in Pakistan came from Dr. Zafar Mirza who gave remarks after relaxation of lockdown, "For the future of Pakistan regarding this pandemic, it will be better if COVID-19 spreads at a certain rate in Pakistan so that people become immune to it" (Dawn 2020). However, if three quarters of the population contract the virus, results would be catastrophic as it can come up with a very high cost (Anderson et al. 2020). Still, the Government of Pakistan is indecisive about the implementation of herd immunity as the disease has killed more than 430,000 people worldwide and the COVID-19 vaccination is years away (Siddique 2020). Allowing the virus to spread among the general public is unacceptable and inhumane as it will require vulnerable community members, immunocompromised citizens, and elderly to be sacrificed to achieve this strategy (Khan 2020b). 
Thus, with each passage of time, the pandemic is amplifying its presence and magnifying its impact on our lives (World Health Organization 2020a) as the number of infections and deaths in Pakistan has risen nearly 500\% (Gul 2020). Providing PPE and resources to healthcare staff in the best possible way helps them fight this pandemic (Kiani and Malik 2020). As COVID-19 is a global healthcare concern that greatly halted the normal life, coping with this phenomenon demands quick and effective decision-making ability. The best approach will be introducing new policies and making influential strategies to bring changes on the grass-root level (Kiani and Malik 2020). Therefore, this pandemic should be accompanied by the realization that health should be treated not as a privilege, but as a right (UN News 2019).

\section{Conclusion}

In a developing country like Pakistan, disease outbreaks greatly challenge the healthcare system. Lack of basic health facilities, insufficient health policies, weak governance, and an indifferent attitude of the public towards general protective measures further worsen the scenario (Jaffery 2020).

The crucial lesson to learn from struggles is that our dilapidated and shabby healthcare system is a finite source. Epidemiology and microbiology lack the exactness of physics. Hence, our experts can provide only guesstimates and advice on management choices. Although Pakistan has limited sources, it can make better use of them. It needs to show a disciplined, clear, tangible, swift, comprehensive, rational, and collective response. This can be achieved by testing a significant proportion of individuals and then isolating those cases after positive test results of COVID-19, introducing PPE, building healthcare capacity, and taking administrative measures to ensure better security is provided to healthcare professionals. Also, to provide resources to healthcare staff in the best possible way helps them fight this pandemic. Fixing primary and secondary healthcare systems is also needed, as they will take the pressure off the tertiary healthcare systems. If major issues in the management system are fixed, a profound impact can be created (Mukhtar 2020).

All provincial authorities and government officials must ensure better security provided to healthcare professionals, spreading awareness campaigns and addressing the fear of citizens.

- Hospital staff must be given utmost protection at all cost before this pandemic could wreak havoc in the healthcare system in terms of infections and fatalities.

- Government must act responsibly educating the public and ensuring the fact that its message must lay out the fact that there is no guarantee that Pakistan's numbers will remain lower than in the West.

- After positive test results of COVID-19, quarantine and social distancing must be aggressively implemented.

- The ramshackle public health sector must get the funding and the priority it deserves.

- Testing, tracking, and lockdown must be focused on areas where clusters have already been detected so infection transmission rate must be locally contained. Meticulously, locate all who might have encountered the virus 


\section{Take-Home Message}

By keeping the current pandemic under consideration, some basic guidelines can help to mitigate the potential impacts of this pandemic. According to the World Health Organization (2020c), sustaining essential practices by following the recommendations can create an impact. Therefore, these guidelines may include the following:

1. Local governments should implement health and social measures to halt the virus transmission by ensuring equal engagement from all members of society. In this regard, the World Health Organization (2020c) suggests media-based campaigns to spread awareness among the public.

2. Evidence showed that COVID-19 can exist in humid places and low temperature for at least 9 days on the surface of shared rooms and areas, i.e., bathrooms, smoking areas, offices, and changing rooms. Using adequate sanitary measures can help to disinfect these areas by using hydrogen peroxide $(0.5 \%)$, ethanol $(61-71 \%)$, or hydrogen hypochlorite $(0.1-0.5 \%)$. Therefore, disinfecting and extra cleaning can greatly help to hinder the virus transmission (Cirrincione et al. 2020).

3. In order to address the specific challenges being faced by Pakistan in responding to the COVID-19 pandemic, we suggest that the following recommendationspermitted from official bodies and existing literature - are a defensible and ethical start for the country to get on track in clamping down on this virus. The government should establish a psychological hotline to provide psychological assistance to active doctors and other medical staff. Moreover, the hospitals' staff should be adequately provided PPE to save them from the infection (Beijing Center for Disease Prevention and Control 2020).

4. Healthcare professionals should be given sufficient training to choose suitable protective equipment as during the current pandemic. They may have a variety of options, but they can find it difficult to choose the appropriate ones (Balachandar et al. 2020).

5. The healthcare professionals should be provided with the basic equipment including N95 and surgical masks, face sheets, and spaces to later dispose of this equipment as (Public Health Ontario 2020) this equipment cannot be reused and if not properly discarded can become a source of virus transmission.

6. Proper collection, transfer, and elimination of waste material is an important concern. Especially, menstrual hygiene material and tissues used for coughing and sneezing should be properly managed. Likewise, the local government should rethink about sanitation system, as public lanterns can also become a potential source of virus transmission. Moreover, human feces can be one of the most common sources of microbial pathogen transmission. In this regard, only a wellmanaged sanitation system would limit transmission of virus especially in developing countries where the governments have to remake its waste management plan (UNICEF 2020).

7. The risk of infection much relies upon the distance to an infected person and the type of facemask worn. From policy debates and research evidence, minimum 1-m physical distancing is highly recommended as a basic protective measure (Chu 
et al. 2020). Due to this reason, keeping an appropriate distance and wearing facemask in public settings, outside of home, are highly recommended measures to prevent the rapid spread of COVID-19 (Centers for Disease Control and Prevention 2020).

\section{Limitations and Recommendations}

This study is based on COVID-19 situational reports, lacking any methodological analysis, which limits its scope. Moreover, due to a limited number of relevant studies in Pakistan, the data is mostly taken from websites of local and national newspapers, which further narrows down its scope. However, the researchers made every possible effort to bring clarity in the topic and recommend studies on theoretical and methodological grounds to highlight the healthcare challenges raised by COVID-19 in Pakistan.

Author Contributions AK conceived the paper and constructed a first draft. SA elaborated arguments and contributed to subsequent drafts of the paper. All authors revised the document for critical intellectual input, and all authors approved the final version.

\section{Compliance with Ethical Standards}

Informed Consent Informed consent was received from all the sources whose data and figures are used.

Conflict of Interest The authors declare that they have no competing interests.

Ethical Approval This study was approved by Sahiwal Medical College Ethical Review Committee and Government of Pakistan.

\section{References}

92 News. 2020. Coronavirus quarantine center with 300 beds established in Islamabad. 92 News HD Plus, 3 March 2020. https://92newshd.tv/coronavirus-quarantine-center-with-300-beds-established-inislamabad/\#.XtOYajllDIV.

Adams, Brad. 2020. Pakistan reopens malls claiming no Covid-19 crisis: response to pandemic is endangering people's health. Human Rights Watch, 19 May 2020. https://www.hrw.org/news/2020/05/19/pakistanreopens-malls-claiming-no-covid-19-crisis.

Adini, Bruria, Avishay Goldberg, Daniel Laor, Robert Cohen, and Yaron Bar-Dayan. 2010. Do standard operating procedures for pandemic influenza impact on emergency preparedness? Prehospital and Disaster Medicine 25 (S1): S25-S25. https://doi.org/10.1017/s1049023x00022329.

Afzal, Madiha. 2020. With a mix of pandemic denialism and exceptionalism, Pakistan makes a cynical bet on the coronavirus. Brookings, 5 June 2020. https://www.brookings.edu/blog/order-from-chaos/2020/06/05 /with-a-mix-of-pandemic-denialism-and-exceptionalism-pakistan-makes-a-cynical-bet-on-thecoronavirus/.

Ahmed, Syed Faraz, Ahmed A. Quadeer, and Matthew R. McKay. 2020. Preliminary identification of potential vaccine targets for the COVID-19 coronavirus (SARS-CoV-2) based on SARS-CoV immunological studies. Viruses 12 (3): 254. https://doi.org/10.3390/v12030254.

Ali, Imtiaz, Syed Ali Shah, and Naveed Siddiqui. 2020. Pakistan confirms first two cases of coronavirus, govt says 'no need to panic'. Dawn, 27 February 2020. https://www.dawn.com/news/1536792. 
Anderson, Roy M., Hans Heesterbeek, Don Klinkenberg, and T. Déirdre Hollingsworth. 2020. How will country-based mitigation measures influence the course of the COVID-19 epidemic? Lancet 395 (10228): 931-934. https://doi.org/10.1016/S0140-6736(20)30567-5.

Armocida, Benedetta, Beatrice Formenti, Silvia Ussai, Francesca Palestra, and Eduardo Missoni. 2020. The Italian health system and the COVID-19 challenge. Lancet Public Health 5 (5): e253. https://doi. org/10.1016/s2468-2667(20)30074-8.

ARY News. 2020. Coronavirus patients, suspects break out of Sukkur quarantine facility. ARY News, 12 March 2020. https://arynews.tv/en/sukkur-quarantine-facility-coronavirus-suspects/.

Balachandar, V., I. Mahalaxmi, J. Kaavya, G. Vivekanandhan, S. Ajithkumar, N. Arul, G. Singaravelu, N. Senthil Kumar, and S. Mohana Devi. 2020. COVID-19: emerging protective measures. European Review for Medical and Pharmacological Sciences 24 (6): 3422-3425. https://doi.org/10.26355 /eurrev_202003_20713.

Beijing Center for Disease Prevention and Control. 2020. Prevention and control measures of COVID-19 in Beijing, China.

Boccia, Stefania, Walter Ricciardi, and John P.A. Ioannidis. 2020. What other countries can learn from Italy during the COVID-19 pandemic. JAMA 180 (7): 927-928. https://doi.org/10.1001 /jamainternmed.2020.1447.

Centers for Disease Control and Prevention. 2020. COVID-19: considerations for wearing cloth face coverings. CDC, 28 June 2020. https:/www.cdc.gov/coronavirus/2019-ncov/prevent-getting-sick/clothface-cover-guidance.html.

Chan, Jasper Fuk-Woo, Shuofeng Yuan, Kin-Hang Kok, Kelvin Kai-Wang To, Hin Chu, Jin Yang, Fanfan Xing, Jieling Liu, Cyril Chik-Yan Yip, Rosana Wing-Shan Poon, Hoi-Wah Tsoi, Simon Kam-Fai Lo, Kwok-Hung Chan, Vincent Kwok-Man Poon, Wan-Mui Chan, Jonathan Daniel Ip, Jian-Piao Cai, Vincent Chi-Chung Cheng, Honglin Chen, Christopher Kim-Ming Hui, Kwok-Yung Yuen. 2020. A familial cluster of pneumonia associated with the 2019 novel coronavirus indicating person-to-person transmission: a study of a family cluster. The Lancet 395 (10223): 514-523. https://doi.org/10.1016 /S0140-6736(20)30154-9

Chaudhry, Asif. 2020. Single Covid-19 patient infects 27 others in Gujrat. Dawn, 29 March 2020. https://www.dawn.com/news/1544552.

Chen, Long, Jing Xiong, Lei Bao, and Yuan Shi. 2020. Convalescent plasma as a potential therapy for COVID-19. Lancet Infectious Diseases 20 (4): 398-400. https://doi.org/10.1016/S1473-3099(20)301419.

Chu, Derek K., Elie A. Akl, Stephanie Duda, Karla Solo, Sally Yaacoub, Holger J. Schünemann, Derek K. $\mathrm{Chu}$, et al. 2020. Physical distancing, face masks, and eye protection to prevent person-to-person transmission of SARS-CoV-2 and COVID-19: a systematic review and meta-analysis. Lancet 395: 1973-1987. https://doi.org/10.1016/s0140-6736(20)31142-9.

Cirrincione, Luigi, Fulvio Plescia, Caterina Ledda, Venerando Rapisarda, Daniela Martorana, Raluca Emilia Moldovan, Kelly Theodoridou, and Emanuele Cannizzaro. 2020. COVID-19 pandemic: prevention and protection measures to be adopted at the workplace. Sustainability 12 (9): 3603. https://doi.org/10.3390 /SU12093603.

Daily Times. 2020a. Total chaos - hospitals in Pak lack facilities to treat corona patients. Daily Times, 27 February 2020. https://dailytimes.com.pk/566099/total-chaos-hospitals-in-pak-lack-facilities-to-treatcorona-patients/.

Daily Times. 2020b. Govt warns stern actions against traders who raise face mask price: Nausheen Hamid. Daily Times, 1 March 2020. https://dailytimes.com.pk/567976/govt-warns-stern-actions-against-traderswho-raise-face-mask-price-nausheen-hamid/.

Dawn. 2020. Herd immunity? Dawn, 10 May 2020. https:/www.dawn.com/news/1555939.

Duan, Kai, Bende Liu, Cesheng Li, Huajun Zhang, Ting Yu, Qu Jieming, Min Zhou, et al. 2020. Effectiveness of convalescent plasma therapy in severe COVID-19 patients. Proceedings of the National Academy of Sciences of the United States of America 117 (17): 9490-9496. https://doi.org/10.1073/pnas.2004168117.

Epstein, Jay, and Thierry Burnouf. 2020. Points to consider in the preparation and transfusion of COVID-19 convalescent plasma. Vox Sanguinis, published online 22 April 2020. https://doi.org/10.1111/vox.12939.

Fine, Paul, Ken Eames, and David L. Heymann. 2011. 'Herd immunity': a rough guide. Clinical Infectious Diseases 52 (7): 911-916. https://doi.org/10.1093/cid/cir007.

Gates, Bill. 2020. Responding to Covid-19 - a once-in-a-century pandemic? New England Journal of Medicine 382: 1677-1679. https://doi.org/10.1056/NEJMp2003762.

Government of Pakistan. 2020a. Current policies. COVID-19 health advisory platform by the Ministry of National Health Services Regulations and Coordination. Accessed 12 July 2020. http://covid.gov. pk/stats/pakistan. 
Government of Pakistan. 2020b. Pakistan cases details. COVID-19 health advisory platform by the Ministry of National Health Services Regulations and Coordination. Accessed 12 July 2020. http:/covid.gov. $\mathrm{pk} /$ intl_travellers/current_policies.

Greenberg, Neil, Mary Docherty, Sam Gnanapragasam, and Simon Wessely. 2020. Managing mental health challenges faced by healthcare workers during Covid-19 pandemic. BMJ 368: m1211. https://doi. org/10.1136/bmj.m1211.

Greenfield, Charlotte and Umar Farooq. 2020. After Pakistan's lockdown gamble, COVID-19 cases surge. Reuters, 5 June 2020. https://www.reuters.com/article/us-health-coronavirus-pakistan-lockdown/afterpakistans-lockdown-gamble-covid-19-cases-surge-idUSKBN23C0NW.

Gul, Ayazgul. 2020. COVID-19 infections rise nearly 500\% in Pakistan. Voice of America, 3 June 2020. https://www.voanews.com/covid-19-pandemic/covid-19-infections-rise-nearly-500-pakistan.

Hadid, Diaa, and Abdul Sattar. 2020. Pandemic panic in Pakistan: 'people are just literally fighting for beds'. National Public Radio, 19 June 2020. https:/www.npr.org/sections/goatsandsoda/2020/06/19/878896370 /pandemic-panic-in-pakistan-people-are-just-literally-fighting-for-beds.

Hashim, Asad. 2020a. Pakistan hospitals struggle as coronavirus cases explode. Al Jazeera, 12 June 2020. https://www.aljazeera.com/indepth/features/pakistan-hospitals-struggle-coronavirus-cases-explode200612084123797.html.

Hashim, Asad. 2020b. WHO says Pakistan should reimpose lockdown to curb coronavirus. Al Jazeera, 10 June 2020. https://www.aljazeera.com/news/2020/06/pakistan-reimpose-lockdown-curb-coronavirus200610093521629.html.

Hayat, Khezar, Meagen Rosenthal, Sen Xu, Muhammad Arshed, Pengchao Li, Panpan Zhai, Gebrehaweria Kassa Desalegn, and Fang Yu. 2020. View of Pakistani residents toward coronavirus disease (COVID19) during a rapid outbreak: a rapid online survey. International Journal of Environmental Research and Public Health 17 (10): 1-10. https://doi.org/10.3390/ijerph17103347.

Husain, Fahd. 2020. Is Pakistan considering herd immunity? Dawn, 15 May 2020. https://www.dawn. com/news/1556710.

Isaacs, David, Henry Kilham, Julie Leask, and Bernadette Tobin. 2009. Ethical issues in immunisation. Vaccine 27 (5): 615-618. https://doi.org/10.1016/j.vaccine.2008.11.002.

Jaffery, Rabiya. 2020. Pakistan struggles to fight COVID-19. The Diplomat, 15 April 2020. https://hediplomat.com/2020/04/pakistan-struggles-to-fight-covid-19/.

Javed, Bilal, Abdullah Sarwer, Erik B. Soto, and Zia-ur-Rehman Mashwani. 2020. Is Pakistan's response to coronavirus (SARS-CoV-2) adequate to prevent an outbreak? Frontiers in Medicine 7: 7-10. https://doi. org/10.3389/fmed.2020.00158.

Kermani, Secunder. 2020. Coronavirus: rumours, fear and rising Covid deaths in Pakistan. BBC News, 2020. https://www.bbc.com/news/world-asia-52925286.

Khan, Asim. 2020a. Coronavirus quarantine centre at Pak-Iran border runs out of space. SAMAA, 5 March 2020. https://www.samaa.tv/news/pakistan/2020/03/coronavirus-quarantine-centre-at-pak-iranborder-runs-out-of-space/.

Khan, Mishal Samar. 2020b. Questions about Pakistan's Covid-19 control strategy. The News, 21 June 2020. https://www.thenews.com.pk/tns/detail/674891-questions-about-pakistans-covid-19.

Khanain, Wajiha. 2020. Pakistan now equipped to test for novel coronavirus, says PM's aide. Dawn, 12 February 2020. https://www.dawn.com/news/1532077.

Daud Khattak. 2020. Pakistan's confused COVID-19 response. The Diplomat, 9 June 2020. https://thediplomat.com/2020/06/pakistans-confused-covid-19-response/.

Kiani, Shafaq and Javed Malik. 2020. How local government can strengthen Pakistan's fight against Covid19: Democracy Reporting International. Democracy Reporting International, 16 April 2020. https:/democracy-reporting.org/dri publications/how-local-government-can-strengthen-pakistans-fightagainst-covid-19/.

Lai, Chih Cheng, Cheng Yi Wang, Ya Hui Wang, Shun Chung Hsueh, Wen Chien Ko, and Po Ren Hsueh. 2020. Global epidemiology of coronavirus disease 2019 (COVID-19): disease incidence, daily cumulative index, mortality, and their association with country healthcare resources and economic status. International Journal of Antimicrobial Agents 55 (4): 105946. https://doi.org/10.1016/j. ijantimicag.2020.105946.

Latif, Aamir. 2020a. Pakistan: lifting virus lockdown may lead to 'herd immunity.' Anadolu Agency, 14 May 2020. https:/www.aa.com.tr/en/asia-pacific/pakistan-lifting-virus-lockdown-may-lead-to-herdimmunity/1840326.

Latif, Aamir. 2020b. Pakistan reports death of 3rd doctor from coronavirus. Anadolu Agency, 6 April 2020. https://www.aa.com.tr/en/asia-pacific/pakistan-reports-death-of-3rd-doctor-from-coronavirus/1794673. 
Liu, Wei, Xiao Guang Yue, and Paul B. Tchounwou. 2020. Response to the Covid-19 epidemic: the Chinese experience and implications for other countries. International Journal of Environmental Research and Public Health 17 (7): 1-6. https://doi.org/10.3390/IJERPH17072304.

Mukhtar, Sonia. 2020. Pakistanis' mental health during the COVID-19. Asian Journal of Psychiatry, published online 23 April 2020. https://doi.org/10.1016/j.ajp.2020.102127.

Nafees, Mohammad, and Farukh Khan. 2020. Pakistan's response to COVID-19 pandemic and efficacy of quarantine and partial lockdown: a review. Electronic Journal of General Medicine 17 (6): em240. https://doi.org/10.29333/ejgm/7951.

Noreen, Nadia, Saima Dil, Saeed Ullah Khan Niazi, Irum Naveed, Naveed Ullah Khan, Farida Khudaid Khan, Shehla Tabbasum, and Deepak Kumar. 2020. COVID-19 pandemic \& Pakistan; limitations and gaps. Global Biosecurity 1 (4). https://doi.org/10.31646/gbio.63.

Primary \& Secondary Health Care Department, Government of Punjab. 2020. COVID-19 notification/SOPS \& guidelines. https://pshealth.punjab.gov.pk/Home/Covid19SopsGuidelines.

Prompetchara, Eakachai, Chutitorn Ketloy, and Tanapat Palaga. 2020. Immune responses in COVID-19 and potential vaccines: lessons learned from SARS and MERS epidemic. Asian Pacific Journal of Allergy and Immunology 38 (1): 1-9. https://doi.org/10.12932/AP-200220-0772.

Public Health Ontario. 2020. IPAC recommendations for use of personal protective equipment for care of individuals with suspect or confirmed COVID-19. Toronto, ON: Queens's Printer for Ontario. Accessed 12 July 2020. https://www.publichealthontario.ca/-/media/documents/ncov/updated-ipac-measures-covid19.pdf?la=en.

Qureshi, Zubair. 2020. COVID-19: ‘breakthrough’ drug dexamethasone running short in Pakistan markets. Gulf News, 19 June 2020. https://gulfnews.com/world/asia/pakistan/covid-19-breakthrough-drugdexamethasone-running-short-in-pakistan-markets-1.72136756.

Raza, Sohail, Muhammad Asif Rasheed, and Muhammad Khalid Rashid. 2020. Transmission potential and severity of COVID-19 in Pakistan. Preprints 2020040004. https://doi.org/10.20944 /preprints202004.0004.v1.

Sanders, James M., Marguerite L. Monogue, Tomasz Z. Jodlowski, and James B. Cutrell. 2020. Pharmacologic treatments for coronavirus disease 2019 (COVID-19): a review. JAMA 323 (18): 1824 1836. https://doi.org/10.1001/jama.2020.6019.

Saqlain, Muhammad, Muhammad Muddasir Munir, Ali Ahmed, Azhar Hussain Tahir, and Sohail Kamran. 2020. Is Pakistan prepared to tackle the coronavirus epidemic? Drugs and Therapy Perspectives 36 (5): 213-214. https://doi.org/10.1007/s40267-020-00721-1.

Shanafelt, Tait, Jonathan Ripp, and Mickey Trockel. 2020. Understanding and addressing sources of anxiety among health care professionals during the COVID-19 pandemic. JAMA 323 (21): 2133-2134. https://doi.org/10.1001/jama.2020.5893.

Siddique, Abubakar. 2020. By inaction, Pakistan looks to be choosing herd immunity as coronavirus response. Gandhara, 15 June 2020. https://gandhara.rferl.org/a/by-inaction-pakistan-looks-to-be-choosing-herdimmunity-as-coronavirus-response/30672411.html.

Singh, Madhav Madhusudan. 2019. What are the SOPs (standard operating procedures) and its benefits? Research Foundation of Hospital and Healthcare Administration. Accessed 13 July 2020. https://www. researchgate.net/publication/337074540.

Spinelli, A., and G. Pellino. 2020. COVID-19 pandemic: perspectives on an unfolding crisis. British Journal of Surgery 107 (7): 785-787. https://doi.org/10.1002/bjs.11627.

UN News. 2019. 'Health is a right, not a privilege' says WHO chief on World Health Day. UN News, 7 April 2019. https://news.un.org/en/story/2019/04/1036221.

UNICEF. 2020. COVID-19 emergency preparedness and response WASH and infection prevention and control measures in schools. UNICEF, 25 March 2020. Accessed 13 July 2020. https://www.unicef. org/documents/wash-and-infection-prevention-and-control-measures-schools.

United Nations. 2020. United Nations guidance note on addressing and countering COVID-19 related hate speech. United Nations Office on Genocide Prevention and the Responsibility to Protect, 11 May 2020. https://www.un.org/en/genocideprevention/publications-and-resources.shtml

ur-Rehman, Zia, Maria Abi-Habib, and Ihsanullah Tipu Mehsud. 2020. 'God will protect us': coronavirus spreads through an already struggling Pakistan. New York Times, 26 March 2020. https://www.nytimes. com/2020/03/26/world/asia/pakistan-coronavirus-tablighi-jamaat.html.

Waris, A., U.K. Atta, M. Ali, A. Asmat, and A. Baset. 2020. COVID-19 outbreak: current scenario of Pakistan. New Microbes and New Infections 35: 100681. https://doi.org/10.1016/j.nmni.2020.100681.

World Health Organization. 2020a. Coronavirus (COVID-19) events as they happen. Accessed 13 July 2020. https://www.who.int/emergencies/diseases/novel-coronavirus-2019/events-as-they-happen. 
World Health Organization. 2020b. WHO coronavirus disease (COVID-19) dashboard. Accessed 13 July 2020. https://covid19.who.int/.

World Health Organization. 2020c. 2019 novel coronavirus (2019-nCoV): strategic preparedness and response plan. 3 February 2020. Geneva: World Health Organization. Accessed 13 July 2020. https://www.who.int/publications/i/item/strategic-preparedness-and-response-plan-for-the-newcoronavirus.

World Health Organization Regional Office Africa. 2014. Standard operating procedures for coordinating public health event preparedness and response in the WHO African region. Brazzaville: World Health Organization Regional Office Africa. Accessed 13 July 2020. http://www.who. int/hac/techguidance/tools/standard_operating_procedures_african_region_en_2014.pdf.

Yang, Penghui, and Xiliang Wang. 2020. COVID-19: a new challenge for human beings. Cellular and molecular immunology 17 (5): 555-557. https://doi.org/10.1038/s41423-020-0407-x.

Yi, Ye, Philip N.P. Lagniton, Sen Ye, Enqin Li, and Ren-He Xu. 2020. COVID-19: what has been learned and to be learned about the novel coronavirus disease. International Journal of Biological Sciences 16 (10): 1753-1766. https://doi.org/10.7150/ijbs.45134.

Publisher's Note Springer Nature remains neutral with regard to jurisdictional claims in published maps and institutional affiliations. 